\title{
Globalisation and Higher Education Research
}

Eric Beerkens

Globalisation has become one of the key concepts in the social sciences today. In higher education research, too, the term is used frequently. Maybe even so frequently that it sometimes seems possible to pronounce virtually anything under the heading of globalisation. This article attempts to identify the various interpretations of globalisation in general, as well as in higher education research. It will do so in an interdisciplinary manner. The different interpretations of globalisation are related to the different past realities that are taken as a point of departure. Four different conceptualisations are identified and will be further explored. These are also explored for the field of higher education research. The following broad topics are identified in this field: the changing nature of international linkages, government authority over higher education, threats to diversity, and the loss of national identities.

Keywords: Higher education; internationalisation; globalisation; theoretical perspectives on globalisation

Globalisation has become one of the key concepts in the social sciences at the turn of the century. As with many new and fashionable catchwords, the use of the term globalisation has created for us an opportunity to understand current phenomena, but it has at the same time caused for great confusion. International relations scholar Jan Aart Scholte (1997) illustrated this by stating that

ideas of "globalization" are so broad, so diverse, and so changeable that it sometimes seems possible to pronounce virtually anything on the subject. Although this danger is clearly present, notions of "globalization" can-when developed with care, precision, consistency, and suitable qualifications-be more than an intellectual gimmick. (p. 248)

To achieve a good understanding of how globalisation relates to higher education, we will make an attempt to develop a notion of globalisation in such a careful, precise,

Journal of Studies in International Education, Vol. 7 No. 2, Summer 2003 128-148 DOI: $10.1177 / 1028315303251395$

(C) 2003 Association for Studies in International Education 
and consistent way. A meticulous understanding of the term requires an interdisciplinary view. In this article, we will try to develop such an interdisciplinary conceptualisation of globalisation. After exploring the concept, we will look at how this concept can and has been applied in the higher education literature.

\section{THE GLOBALISATION CONTAINER}

In the past decade, the concept of globalisation yielded a vast amount of literature and has also led to an extensive list of interpretations of this process. The trouble in conceptualising the term globalisation is partly due to the wide range of disciplines that have focused on this process. One could say that the first notions about interdependency at the global level have been addressed by political geographers focusing on geopolitics and by international relation theorists, with MacKinder (1904) or Angell (1911) being some of the first to acknowledge an interdependent political system of worldwide scope. Or maybe even the work of Marx and Engels who in the mid-19th century already talked about the "universal interdependence of nations." That globalisation is by many understood as more than interdependence among nation-states is illustrated by the globalisation literature of the 1990s, coming mainly from the disciplines of political science, sociology, anthropology, management, and economics. Many authors have attempted to explain changes in the contemporary world by referring to the term globalisation. What can be concluded from the vast increase in literature on globalisation is that something is happening, something new that differentiates it from previous times. The nature and intensity of change, however, seems to cause great disagreement. I propose that these differences exist because the present changes are approached from several past realities because authors have attempted to explain the process of globalisation by distinguishing it from the past state of affairs and using as a point of departure a past given. This proposition is validated by the various temporal scopes chosen to determine the presence or absence of the globalisation process and the different perceptions of its existence. If we talk about changes, we cannot compare statements about these changes if they use different points of reference. These points of reference will be further analysed in the next section.

\section{One Word Fits All?}

Looking at the wide range of interpretations of the process of globalisation, one could claim that there would always be one that would fit your research (or your political agenda). To analyse what this (new) process could mean for the field of higher education, it is first and foremost necessary to bring some order in this maze of perspectives and definitions. On the basis of the literature that has 
attempted to explain or define globalisation, we can distinguish various approaches. What distinguishes these views is the point of reference taken in their description. After all, if we regard globalisation as a process, there must be a so-called past reality that is or has been affected by this process. Classified according to the point of reference taken, we can approach global as a geographical concept distinguishing it from the local, as a concept of authority distinguishing it from territorial sovereignty, as a cultural concept distinguishing it from isolation, and, finally, as an institutional concept distinguishing it from national. These approaches can be and are applied in diverse disciplines. They are dependent on the point of reference taken, not on the disciplinary perspective.

If global is distinguished from local and is conceptualised as worldwide, we emphasise geographical expansion from the local to the global. What has caused us to expand our activities outside our direct surroundings? This expansion, of course, has a long history. Movements of people have existed throughout history, between localities as well as between regions and continents. People have extended their activities for several reasons, ranging from sheer necessity for trade or agriculture to plain curiosity. However, for global expansion of human activities, distance and time posed too many barriers. Since about 1500 A.D., movement of both people and goods became substantial. Intercontinental flows, based on colonial ties, took place more frequently and became more intensive, particularly for spices and raw materials. It took, however, until the beginning of the past century to reach a level at which activities became embedded in a worldwide system. In this approach, a global system was reached around 1900, after which it just became more intense. The main drive for this worldwide expansion was capitalist accumulation through economic trade enabled by naval transport. The growing intensity experienced in the past decades is caused by improvements in speed and capacity in forms of transport. The mechanisation of land and naval transport in the 19th century, the massification of aircraft transport in the latter half of the 20th century, and the digital revolution in the 1990s have led to massive movements of goods, people, finance, and information. This perspective does not question the nation-state but sees it as a part of the world-system of nation-states. What is new at the end of the 20th century is thus not globalisation, because we are already past that, but the intensification of this process and the ongoing transformations of the global system of nation-states.

Globalisation is also discussed in the context of power and authority where it questions the relation between territoriality and jurisdiction. In this discussion, the territorial sovereignty and authority of the nation-state is at stake. There are wide differences in opinion on the reality of this process of deterritorialisation or denationalisation. Kenichi Ohmae $(1992,1995)$ is probably the best-known 
defender of the denationalisation thesis, although Wade (1996) and Hirst and Thompson (1996) are highly sceptical. A more useful and realistic discussion is not centred on whether the nation-state concept is changing but on how it is changing. The frequently mentioned model of the retreating state did not emerge in the context of globalisation but materialized as a response to the overtaxed form of regulatory government in the 1950s and 1960s. New perceptions on the role of the contemporary government, such as the retreating state, the facilitative state, the evaluative state or the interactive state may be accurate in describing the new forms of government, but these do not give explanation for this change of governance in the light of globalisation. In this respect, the concepts of "Competition State" as presented by Cerny $(1997,1999)$ or the adaptation of governments to the capacity for international competition as explained by Habermas (1996) are more suitable. In addition to changes in the nature of national governance, the discussions in this approach also focus on the transfer of authority, either downward (decentralisation to foster competition), upward (to supranational bodies), or to the side (to private nongovernmental actors).

A third conceptualisation of global is related to its cultural meaning. In this respect, globalisation equals the mixing of cultures and its consequences. Here, the direction of globalisation has been fiercely debated. Are we awaiting a "clash of civilisations" (Huntington, 1996) or increasing tensions between Western consumerism and more traditional identities (the Jihad vs. McWorld thesis postulated by Barber, 1996)? These pessimist observations cannot just be refuted, considering recent ethnic conflicts in the world and ethnic tensions within developed multicultural states. This pessimism has risen because of the September 11 tragedy and the subsequent polarisation of perceptions on universalism, tolerance, and multiculturalism. Others, such as Friedman (1999), advocate a more optimistic view and claim that modern culture will triumph without the loss of traditional values. The homogenisation thesis is not only contested by pessimists. Appadurai, for instance, observes a process of cultural mixing and hybridisation across locations and identities. Lash and Urry (1994) noticed that it is necessary to take into account not only global processes of production but also the circumstances in which cultural products are received by audiences. They argue that there is in some respects an increasing contradiction between centralised production and more decentralised and fragmented reception. Even if a process of homogenisation is occurring, the triumph of modern culture (often equated with Western or American culture) is contested. Smith (1990), in this respect, observed an emerging global culture that is tied to no place or period but is contextless: "a true melange of disparate components drawn from everywhere and nowhere" (p. 177). 
Our final conceptualisation of the global entails a more holistic approach. In the use of global as an institutional concept, the logic of national identity, commitment, and citizenship is called into question and is substituted by the emergence of a cosmopolitan identity or citizenship. This goes beyond the notion of a retreating state. Although the long tradition of the national sovereign state has produced several strictly national establishments (courts, parliaments, and so forth), the image of the nation also encompasses arrangements such as citizenship, norms, values, solidarity, and identity. These social arrangements are also being associated with so-called stateness - that is, with being Chinese, Dutch, or American. Some argue, however, that these forms of national commitments are eroding and are being supplanted by other forms of social organisation. What these new forms are remains an arena for intense discussion. Castells (1996, $1997,1998,2000)$, for instance, argues in his theory of the network society that social organisation is now based on information networks. Beck (2000a, 2000b) postulated the existence of a second age of modernity, in which social relations are based on transnational community ties and are no longer supported by place (e.g., neighbourhood), origin (e.g., family), or nation (e.g., state-organised solidarity of citizens). This results in the socialisation of shared risks or shared risk definitions. Sassen $(1991,2000)$ saw national identities replaced by subnational spaces such as cities. Hoogvelt (1998) replaced Wallerstein's distinction of the geographical core-periphery partition for the social core-periphery partition. Appadurai $(1990,1996)$ observed that they are shaped by different landscapesethnoscapes, mediascapes, technoscapes, finanscapes, and ideoscapes-as building blocks of imagined worlds. Global flows, according to him, occur in and through the growing disjunctures between these landscapes. This has been a long historical process, but because of the speed, scale, and volume of these global flows, these disjunctures become evident and central to the politics of global culture. Because globalisation in this sense can be seen as the supplanting of national identity and commitment, it is also incorporated in Robertson's (1992) definition of globalisation. He claimed that the process does not simply refer to an objective process of greater interconnectedness but also to conscious and subjective matters, namely the scope and density of the consciousness of the world as a whole. The growing awareness of environmental risks-exemplified by the title of the Brundtland report, "Our Common Future"—can be seen as the origin of this global consciousness. The resulting new perspectives on social structures are detached from nationality space or kinship, leading to cosmopolitan societies formed around networks, risks, or themes. The basic thesis in this approach is that social cohesiveness is no longer embedded in national institutions but is being substituted for some form of cosmopolitan solidarity. To reach 
this outcome, however, national institutions that have provided this cohesiveness need to be supplanted by global institutions.

In the different approaches on globalisation, which are only shortly, and therefore incompletely, discussed here, the main disagreement is between the notion of global as a geographical concept on one hand and as an authorityrelated, cultural, and institutional concept on the other. Although the first regards contemporary changes as intensification and alteration of international relations within the world-system-which came into being more than a century ago- the other three consider contemporary changes as more revolutionary. In the cultural conceptualisation of the global, this is mainly an acceleration of a long historical process, whereas the power and institutional perceptions of globalisation see it mainly as a postwar process accelerated through greater interconnectedness. In the geographical or geopolitical view, the process started with the emergence of transcontinental movements of people and goodsmainly based on the logic of capital accumulation — and reached its completion in the beginning of the 20th century. Main historical events in this respect are the processes of colonisation and the improvements in transport during the industrial revolution. Many contest this notion of globalisation by addressing that national sovereignty is still considered as the core of the world-system. In our view, this is mainly a discussion about the nominal meaning of the word globalisation. If authors say that this word means worldwide interconnectedness, the process was indeed completed a long time ago. In that case, current changes merely alter and deepen these relations because of further capitalist accumulation, more advanced technologies, and the deregulation of markets. The other conceptions of globalisation contest this meaning of the word.

This can be illustrated by pointing to the main historical events that have occurred according to the different views on globalisation. Those who see it as a concept related to territorial jurisdiction and power start their analysis by referring to the Westphalian order that emerged in 1648 and eventually crystallised into the postwar welfare states of the 1950s, 1960s, and 1970s. The so-called Thatcherism and Reaganomics of the 1980s represented a shift with delegating more authority from the state to the market. After the decline of communism, new constellations emerged, embodied by terms such as the Third Way, the New Democrats, or the Neue Mitte, which sought new forms of government beyond state or market, ultimately resulting in the Competition State in the 1990s. Simultaneously, in Europe, an upward transfer of authority took place during a long process beginning with the Schumann Plan in 1950 and still evolving at this moment. Although the transfer of authority toward the EU has gone much further than anywhere else, it also took place in other regions such as the SADC, Mercosur, and ASEAN regions. Those using globalisation as a cultural concept 
Table I Different Perspectives on Globalisation

\begin{tabular}{|c|c|c|c|}
\hline Conceptualisation & Past Reality & New Reality & Globalisation Equals \\
\hline Geographical & Unconnected localities & $\begin{array}{l}\text { The world-system that } \\
\text { came into existence } \\
\text { around } 1900\end{array}$ & $\begin{array}{l}\text { Increasing } \\
\text { interconnectedness }\end{array}$ \\
\hline Authority & $\begin{array}{l}\text { State sovereignty over } \\
\text { clearly defined } \\
\text { territories }\end{array}$ & $\begin{array}{l}\text { Authority transferred } \\
\text { upward, downward, } \\
\text { and sideways }\end{array}$ & Deterritorialisation \\
\hline Cultural & $\begin{array}{l}\text { Mosaic of cultures } \\
\text { without significant } \\
\text { routes for cross- } \\
\text { cultural exchange }\end{array}$ & Melange of cultures & $\begin{array}{l}\text { Either uniformity } \\
\text { or friction }\end{array}$ \\
\hline Institutional & $\begin{array}{l}\text { Nation as the } \\
\text { institutional container } \\
\text { of society: Identity, } \\
\text { solidarity, and } \\
\text { citizenship based on } \\
\text { nationality }\end{array}$ & $\begin{array}{l}\text { Social organisation and } \\
\text { identity structured } \\
\text { around aspatial } \\
\text { systems }\end{array}$ & Cosmopolitanisation \\
\hline
\end{tabular}

use a longer time span, taking the spread of Christendom or Islam as a starting point. Western imperialism constitutes another important period in history. But also in this approach, postwar developments, and mainly those in the last two decades of the 20th century, are seen as a causing a historical turning point. Important channels in this respect are the worldwide coverage of events, the spread of Western consumer products, increasing and altering migration patterns, and communication and information technologies all leading to both homogenising forces as well as inclinations toward traditional values or fundamentalist movements. The historical events that are considered important in the process of globalisation as an institutional concept leading to the emergence of cosmopolitan societies are those that have created a sense of global citizenship through the awareness of the world as a whole. Here, we can think of the establishment of the League of Nations, the first outer space expeditions and the landing on the moon, the notion of "spaceship Earth" embodied in the Brundtland Report, the emergence of several-globally operating-nongovernmental organisations, the direct coverage of the fall of the Berlin Wall, and the shifts in the interpretation of international law in recent international disputes. Even war and justice are becoming detached from the institutions of the nation-state, with war being declared not just to other nations but also to transnational (terrorist) networks. The main differences between the four approaches are summarised in Table 1. 


\section{From Expansion to Implosion}

What can we now conclude from the various views above? They make clear that globalisation is not a one-dimensional development. Neither should it be seen as a process caused or driven by one cause or logic. Even though the accumulation of capital and the associated international division of labour stood at the basis of the emergence of a worldwide system of nation-states, this system was, in the course of the 19th and 20th centuries, supplemented by a wide international political system, with the League of Nations and the United Nations framework as its most global offshoots. These new players in the international political system did not all emerge because of the integration of markets but were also driven by the various threats of war and by the understanding that various problems called for the collective action of nation-states. These developments, the integration of markets, an international division of labour, the threat of war, and the awareness of global or transnational problems and risks had in the late 19 th century created a highly interrelated and interdependent system in which nation-states, a small amount of multinationals, and various international organisations were the major players.

In the period after the Second World War, however, some major changes occurred that affected this system. First of all, countries involved in the war were preoccupied with domestic problems. The European nation-states and the United States were investing in reconstruction, ultimately resulting in the welfare states of the 1960s and 1970s. The main international interaction in this period was in the form of reconstruction programmes and in finding international structures that would contribute to the prevention of wars. The world market, however, that had existed before the two World Wars became less integrated than at the turn of the century. A second key development was the emergence of the bipolar world, which divided the world market in two, leading to further disintegration. A third major change took place in what is now known as the South. The decolonisation process in the 1950s and 1960s resulted in an increase in the players on the world market and created, next to the East-West divide, the NorthSouth divide, two parts that were formerly kept together in the colonial world market.

This situation sets the stage for investigating the process of globalisation, a world divided by ideology, a world divided by socioeconomic factors with the relatively wealthy and stable North (with countries focusing on balancing internal economic growth and social solidarity) on one hand and the countries of the South (marked by political turmoil, cultural confusion, and economic backwardness) on the other. But also a world united by threats, trade, and telephone lines. Then the question becomes, What happened in the last quarter of the 20th century that makes us observe a process of globalisation? Some events of the late 
1970s and the 1980s are crucial in this respect. First, the welfare states that emerged in the West during the postwar period started to show some cracks and, because of economic recessions, countries became aware of the notion that the welfare state in its current form was not sustainable and that the market had to be brought back in to keep economic growth at the required level. Led by the Thatcher and Reagan administrations, this mainly meant a liberalisation of domestic markets. Simultaneously, however, measures were also taken to facilitate trade between the nations of the West, that is, North America, Western Europe, Australia, and Japan. This relatively simple structure of the world market, however, changed radically through the economic development of several countries in the 1970s and 1980s and through the liberalisation of financial markets in developing countries since the mid-1980s. These countries in the South, the newly industrialised countries (NICs) of Latin America and Asia, created both an outlet for further capitalist expansion of Western countries and a new market for consumer products, as well as an optimistic awareness that markets and societies in the South could be integrated in the world market on an equal level. A third development in this period contributing to the process of globalisation was the emergence of global problems, mainly environmental. The acidification of Scandinavian forests caused by Western European industries, the transnational consequences of the Tsjernobyl incident, the hole in the ozone layer, and the deterioration of rainforests in the South due to increased global expulsion of carbon dioxide created the notions of a common future and a spaceship earth, which increased global awareness. Increased migration and tourism and worldwide TV coverage of events further contributed to this awareness. One of such events, and the final development that contributed to the increased interconnectedness on a global scale, was, of course, the decline of communism illustrated by the tearing down of the Berlin Wall. These events constituted the world at the beginning of the 1990s: increased pressures on the welfare state, the awareness of Third World and Second World consumer markets and investment outlets, increased international trade that - through the liberalisation of markets-extended to actual presence of foreign companies in other countries, and an increased one-world awareness. This state of the world, instead of representing the end of history, formed a fertile breeding ground for what is now often discussed under the banner of globalisation. What was needed now was for flows of people, products, finance, images, and information to become faster, more massive, more flexible, and more extensive. This was made possible in the 1990s through massification of existing technologies (aircraft, TV, satellite) and the wide introduction of new information and communication technologies. What happened was suddenly referred to as globalisation, first by business gurus and by academics, later also by the media, politics, and activists. 
If we look at the literal meanings of the word global—which are "worldwide" and "all-inclusive" (globalisation therefore refers to "making or becoming worldwide or "making or becoming all-inclusive")—one might conclude that a phase of expansive globalisation (in the sense of "making worldwide") had been completed around the turn of the 19th and 20th centuries. In this point of history, we witnessed a world of interconnected nation-states. A second period of globalisation (in the meaning of all-inclusive) took off in the last quarter of the 20th century and was reinforced through the acceleration, massification, flexibilisation, and expansion of flows of people, products, finance, images, and information. So far, there is nothing revolutionary about globalisation, it is just faster, more massive, and wider. Its potential consequences, however, are perceived as revolutionary by the globalists who observe a process in the direction of denationalisation, homogenisation, or cosmopolitanisation. The contemporary world (or, should we say, the previous world?) is so much entangled with the compartmentalisation of its economies, cultures, power bases, and identities that a geographical extension toward the global level is almost seen as an absurdity. We are so accustomed to our spatially confined compartments (which used to form the container for our power bases, economies, identities, citizenship, and culture), that the decline of the boundaries between these compartments demands entirely new perspectives on politics, on society, on culture, and on economies. After all, authority, law, identity, culture, solidarity, and so forth are still primarily associated with nation-states. And even today's multinationals such as Nokia, Philips, and Microsoft are still associated with Finland, the Netherlands, and the United States. A reality in which these fundamental elements of the modern world become disembedded from their spatially confined entities is, however, emerging. This now is what is occurring in the phase of implosive globalisation, emanating from the global interconnectedness between nationstates that emerged in the first phase, but supplemented - and for some authors, ultimately supplanted - by globalisation as a process in which basic social arrangements (such as power, culture, markets, politics, rights, values, norms, ideology, identity, citizenship, and solidarity) become disembedded from their spatial context (mainly, the nation-state) because of the acceleration, massification, flexibilisation, diffusion, and expansion of transnational flows of people, products, finance, images, and information.

\section{Inherent Features of Globalisation}

Although making predictions about the future is not the intention of this article, it is crucial to gain some understanding about the direction of the process. We, therefore, need to understand the processes that are inextricably connected 
with globalisation. In this respect, it is essential to acknowledge that the process of globalisation contains an inner logic by which the prolongation of globalisation can be sustained through its own causes. In other words, intensifying flows invigorates the process of disembedding, which again results in the intensification of flows. From this point of view, however, globalisation would ultimately develop into a tidal wave-that is, if there were no checks and balances attached to this process. But the process of globalisation also intrinsically incorporates local implications and reactions. Economic, political, cultural, and individual actors all jump the bandwagon of globalisation but at the same time are ambiguous in choosing its direction and speed. In an age of globalisation, universalism and particularism, connection and fragmentation, centralisation and decentralisation, conflict and balance are different sides of the same coin. Detachment from spatially confined entities thus also involves a process of reattachment or reembedding. The notion of the Competition State is illustrative in this matter. While promoting the process of globalisation through deregulation of markets and abolition of trade barriers, exposing national economic entities to competition from outside, they simultaneously try to retain the headquarters of their multinationals, maintain images of national airlines and other national industries, retain and create jobs for the national labour force, promote the competitiveness of their citizens in the global knowledge society, and so forth. Other local or regional reactions to the process of globalisation-and also to the narrative of globalisation-in some instances has provoked nationalism, protectionism, conservatism, activism, and (religious) fundamentalism. These reactions to globalisation result in a reattachment to the local contexts from which the social elements were detached due to the process of globalisation.

Another issue that needs to be discussed here is the issue of exclusion. The terms global or globalisation do not mean egalitarian, levelling, or equalisation. In fact, many people see these as opposites. This idea is situated in the concept of flows. Flows redistribute, and massive, fast, and expanded flows redistribute in a more extreme way. At the same time, the idea behind liberalism and free flows is that free flows and the additional redistribution create opportunities for all. That this is merely a theoretical notion has long been recognised. Within nationstates, governments have cultivated a sense of national solidarity in the form of reallocation and levelling of income through the welfare state. In this way, flows were channelled toward equal distribution. It is apparent that the sense of global solidarity is far less cultivated and that the checks and balances are far from developed on a global scale. Our current global welfare-world institutions such as the IMF, the World Bank, the organisations within the UN framework, IGOs and NGOs have proved to be incapable of channelling flows in such a way that an equal distribution comes to pass. This side of globalisation is widely acknowl- 
edged in the literature on globalisation. Castells (1996, 1997, 1998), Bauman (1998), and Hoogvelt (1998), respectively, talked about the exclusion from the unconnected (as opposed to those that are connected), the exclusion of the locally tied (as opposed to the globally mobile), or the social periphery (as opposed to the social core). According to these authors, poverty and wealth also become disembedded from their spatial context. Of course, we can all observe that the poverty of the disconnected, the locally tied, and of the social periphery still shows extensive overlap with geographical location of the poor countries. However-in these views-growing inequality is not only observed between the developed and developing countries but also within these countries, disembedding poverty from its national context and reattaching it to other social constructs. These may be another, non-national, spatial context (e.g., urban ghetto's, peripheral rural areas) or aspatial contexts (e.g., networks, classes).

There are two additional aspects that need to be kept in mind with assessing globalisation. First of all, globalisation does not have to be a uniform process. What is meant here is that not all sectors of society globalise at the same pace. For instance, the telecommunications industry is far more global than most other industries; the economic domain is more globalised than the legal domain, and so forth. This is inherent to the observation that globalisation is a multidimensional process: it is driven by a wide variety of flows and it detaches a wide variety of social arrangements. Another aspect increases the complexity of the process even further. This is the presence of cross-sectoral ties, which means that globalisation and flows in one sector affect the globalisation of other sectors. Globalisation in the fast-food industry affects cultural arrangements; globalisation in business education affects the global economy; globalisation in one sector thus influences globalisation in other sectors. Through these crosssectoral relations and because of the simultaneity of processes of globalisation and localisation and the inner logic, globalisation in one sector can both promote and slow down globalisation in other sectors.

\section{A Note on the Terminology of Crossing Borders}

In discussing globalisation, the terms transnational and international are often applied without clear distinction. The similarity in these two terms is that they both exemplify something that is related to two or more nations. International, however, refers to interconnected arrangements covering the territory of two or more countries, whereas transnational refers to integrated arrangements. The boundary between interconnected and integrated, however, remains unclear. An international market is a market that is connected through relations 
between two or more domestic markets, a transnational market is an integrated market covering parts of the territories of at least two countries. Whether we should talk about an integrated European market or about a highly interconnected market consisting of the domestic markets of the EU nations remains a matter of interpretation. The process from interconnection to integration has also taken place on the national level. When local markets became integrated into national economies cannot be determined precisely. The EU market(s) are now in a similar transition. We suggest that this transformation is based on the acceleration, massification, flexibilisation, diffusion, and expansion of the connections in the form of flows of people, products, finance, images, and information. There, where basic arrangements such as power, solidarity, identity, and so forth, become integrated, we can speak about transnationalisation.

Both transnational and international should not be confused with global. If we again take markets as an example, this can be illustrated by employing our two literal meanings of global. Transnational markets are not at all the same as global markets. Actually, local transnational markets for foods and clothing are very common and can easily be observed in border regions. Such markets become more global when they spread geographically like an oil slick, resembling the strategies of retailers such as A\&P or Ahold or restaurants such as McDonalds and its copycats. International markets are also dissimilar to global markets, namely in two respects. First of all, international markets can exist on a subglobal level. If they extend to a worldwide level, they would constitute a global world-system of national markets, as happened on a macro-level at the end of the 19th century. Another difference between international and global is the above-mentioned distinction between interconnected and integrated. Although we illustrated the differences with markets, this goes for all arrangements organised around flows, such as organisations, networks, media, environment, culture, physical infrastructure, and so forth.

\section{THE CONCEPT OF GLOBALISATION IN HIGHER EDUCATION RESEARCH}

The fact that globalisation is such a comprehensive process and therefore can only be grasped in rather abstract definitions has led — as we saw before- to various conceptualisations of the term globalisation. In higher education research, this has led to a wide range of subjects discussed under the heading of globalisation and higher education. On the basis of the exposé above, an attempt is made to identify the different topics that are covered and detect important issues that lie ahead. 


\section{The Changing Nature of Linkages}

The geographical spread of linkages and the increasing interconnectedness between nations has long affected higher education institutions. In fact, international linkages have always been part of the university. In treating globalisation as a geographical concept that takes unconnected local entities as its past reality, we could argue that higher education has always been international. As we observed in our general exploration of globalisation as a geographical concept, this conceptualisation does not question the matter of national sovereignty but refers to an increasing global interconnectedness. This is the process that in higher education has been referred to as internationalisation. International linkages have been apparent for a long time and reached a global coverage in the late colonial period. Due to political developments, one might say that in the postWorld War era, this global coverage was substituted by an East-West division during the cold war. In this period, the motivations for international linkages were-in addition to the inherent educational motives-mainly cultural and political in nature. In curricular issues, this became apparent in, for instance, area studies, comparative studies, language studies, international law programmes, and so forth. Also in the international flows of students, political motivations became important and strongly regulated by scholarships and exchange schemes. International exchange of students as a political instrument was also used in the case of European integration. More recently, universities have discovered international students as an alternative source of income. Here, the issue of stateness becomes less important. Students do not go to particular nations, but they follow quality and prestige of particular universities. Here, we can detect a similar observation as we discussed above. The interconnectedness between countries becomes more intense, flows become more flexible and more massive, and as a response, nations and higher education institutions have to respond to this massification of student flows. This becomes even more necessary now that these flows no longer need to be physical but can also take the form of information in a digital form. Kälvermark and van der Wende (1997) defined internationalisation of higher education as "any systematic sustained effort aimed at making higher education more responsive to the requirements and challenges related to the globalisation of societies, economy and labour markets" (p. 19). Even though seeing internationalisation as a response to globalisation is in line with our reasoning, we can add that increasing internationalisation can also be seen as a cause for the further globalisation of higher education. This is also coherent with the notion of the inner logic of globalisation that we identified before. 


\section{Losing and Loosening Grip}

When we look at globalisation as the erosion of territorial sovereignty, we look at how the state is losing grip on its higher education institutions, institutions that became very national institutions in the postwar era. Of course, governments are not just losing grip, they are also transferring this grip intentionally-upwards, downwards, and sideways. This transfer is not just a consequence of or an expression of globalisation. It also emanates from the insustainability of the welfare states as we knew them in the decades following the Second World War. We already pointed to the fact that we were discussing notions of the retreating state well before we mentioned the process of globalisation. This also goes for the governance of higher education. The main issues in this category of research should therefore focus on two main issues. First, it should question how supranational and transnational institutions are getting a grip on higher education because of increased international flows and whether this transfer is undermining national authority in higher education. A second core issue is the changing relation between the state and higher education because of globalisation in other sectors.

Flows in higher education can take on different forms: flows of students, flows of graduates, flows of information and course materials, flows of academic labour, flows of financial resources, and so forth. The increase in student mobility and the international opportunities for graduates have led to an increased demand for transparency and comparability of quality, credits, certification, and degrees. Also, the provision of courses and programmes across national borders through online education or students physically obtaining higher education in other countries cannot just be ignored by national governments. Through these developments, their higher education policies can no longer be just based on national circumstances or benchmarked on national norms. Global competition on the labour market diminishes the power of governments to discretely set requirements for their graduates. They now find competition in this domain by other governments and by professional accreditation bodies. They also lose their control on higher education through their previous function as sole (or main) provider of financial resources. Universities diversify their funding bases not just within the national domain but also internationally through research foundations, international business, supranational providers of resources, and by acquiring tuition fees from international students. In many countries, the government's control on its higher education to a large extent took place through their function as the provider of financial resources and as legislator. In both these core functions, national governments are losing influence. This does not necessarily mean that governments are actually losing in this respect. 
Governments-in governing the competition state-are actively involved in the transfer of authority. They transfer authority and responsibilities to higher education institutions, to regional, supranational bodies, and to the private sector. They need to do this to give in to the reality of the increasing claims on public funds and the decreasing proportion that is available for higher education. But governments also actively try to improve the international position of their economies and strive for national educational and scientific excellence. To achieve this, they act collectively (e.g., in the EU framework) or actively promote the competitive position of their universities by encouraging the exploration of new student markets and by providing (financial) stimuli for increasing competition between their national higher education institutions. Furthermore, to improve or retain its position in the globalised markets for finance, commodities, services, and labour, the quality of education and the availability of knowledge gains importance. Governments, therefore, want to obtain the best researchers and the best students for their universities to become the best universities that provide the best labour force, compatible with the demands of the knowledge economies. This is motivating them to open up their borders, which at the same time makes them vulnerable to foreign competition. The current GATS negotiations illustrate this paradox of the competition state, in which opening up both offers opportunities for increasing national strengths but also presents severe threats to the authority of nations over its higher education.

An additional theme in the discussion on higher education and globalisation in the sense of the deterioration of national sovereignty is apparent in the dialogue on higher education in developing countries and the influence of international institutions such as development banks and the IMF and bilateral and multilateral forms of development assistance. Usually, access to financial resources does come with strings attached. Action programmes on higher education, but also more general action programmes and financial rescue packages, come with requirements on changes in the education sector or the public sector as a whole (e.g., strict monetary policies, privatisation, decentralisation). Although nationstates allegedly have the choice to accept these packages (including the requirements), in reality, several countries are not in the position to reject such packages. This does not mean that certain principles that are usually included in such policies (e.g., greater institutional autonomy, increase of efficiency) are not compatible with the demands of higher education in developing countries. It does, however, constitute an implicit loss of authority of governments on their higher education policies. Whether the transfer of specific models to developing countries is effective or desirable is a major topic in this theme. Studies in this area also touch on the more cultural conceptualisation of globalisation. 


\section{Threats to Diversity?}

The homogenisation or convergence thesis, which is often posited in cultural conceptualisations of globalisation, can refer to many aspects of higher education-the organisational form of higher education institutions, the structure of education systems, curricula, and so forth. The homogenisation thesis in the current discussion in relation to globalisation is often centred on a fear of homogenisation of content and the export of policy and management discourses. Examples of the first issue are, for instance, illustrated by the spread of the use of English as a language of instruction and research or the disappearance of particular studies at the expense of others. In the case of policy and management, models and fashions rapidly diffuse across persons, organisations, and nations, which do not necessarily evaluate the promises of rationality and efficiency that typically accompany such fashions. Examples of the worldwide diffusion of policy and management discourses are abundant. We can think of the current higher education policy discourse, in which models such as the so-called entrepreneurial university are spreading worldwide. In a similar fashion, one can also refer to concepts such as new public management, total quality management, or studentcentred learning that represent culturally legitimate models. In higher education, as in many other sectors, homogenisation is often feared for, although diversity is something that ought to be aspired to. In this respect, there is a natural tension between the advantages of mutual adjustment and comparability of systems on one hand and the amenities of indigenous or traditional strengths on the other. This discussion is often very normative, expressing fears of McDonaldisation of higher education or academic colonialism. In the policy and management domain, this discourse often is highly sceptic about the influence of international agencies such as the Worldbank, IMF, or agreements such as the GATS, that are seen as the actors pushing for specific models in developing countries. But also in the developed countries, there is a fear for convergence through increasing importance of market forces in higher education (Currie, 1998). Concerns of competition also played a role in the harmonisation of qualification structures in the framework of the Bologna process in Europe (van der Wende, 2001). In addition to states, universities are also seen as agents in this process through the expansion of their boundaries by establishing off-shore campuses and franchise agreements outside their national boundaries.

\section{Global U?}

Our final conceptualisation of globalisation as cosmopolitanisation would suggest that higher education, its institutions, and their students and staff are los- 
ing their national identity and base their identity on features other than their nationality. In this conceptualisation, the past reality of the university is that of an institution that was born of the nation-state and it had, and still has, a national regulatory and funding context, a significant contribution to national culture, and it trains students to become national functionaries (Enders \& Fulton, 2002, pp. 3-4). On the policy level however, one can observe a shift in national policies on higher education where national identity is losing influence. This is related to the fact that governments are loosening their grip on higher education. Higher education has long been used as a way of nation building. Universities were not just educational institutions but also protected the national cultural heritage and provided the future leaders for the national society and economy. Many (but by no means all) universities nowadays offer education as a service that is not tied to a specific locality or nation but that has become a commodity for individual investment that can be purchased either in the country of residence, in other countries, or in the virtual world. Even where higher education is still used as an instrument for creating cultural, social, or economic cohesiveness, this has sometimes been transferred upwards-such as, for instance, in the European Union (through the Erasmus and Socrates programmes) - but also in other economic or political regional blocks. The change of character at the expense of national identity is also apparent in universities as organisations. Most universities were and still are very much national institutions. Many institutions, however, are expanding their relations and even their organisational boundaries toward regional or global levels. Universities are engaging in several international networks and associations based on their similar identities, not their nationalities (Beerkens, 2002). Several universities even globalise by establishing branches in other countries. Although these foreign campuses often still need to comply with national legislation on curriculum content and language of instruction, governments are loosening these restrictions to keep students in their countries or because of their incapacity to regulate distance education. In this way, many universities are losing part of their national identity, substituting it by a global identity for some and regional or local identity for others. To what extent loss on the one side (traditional values, cultural heritage, and so forth) is compensated by benefits on the other (international awareness, knowledge about cross-cultural issues, comparability, and transparency) is debatable.

\section{CONCLUDING REMARKS}

The discussion of the various conceptualisations of globalisation and their applications in higher education research illustrate the broad field that can be placed under this heading. Universities are objects as well as subjects, they influence and at the same time are affected by the process of globalisation (Scott, 
1998, p. 122). Universities become disembedded from their national context because of more intense flows. At the same time, this provokes further globalisation of higher education and of other sectors. Another point made by Scott is that all universities are subject to the same process of globalisation. Although one might claim that there is an all-embracing process of globalisation (which is not a useful concept), universities are affected differently by and contribute differently to globalisation of different arrangements. Universities react differently to the globalisation of the economy than to the globalisation of environmental pressures and contribute differently to the globalisation of business than to the globalisation of activism. It is even so that different groups within the university are differently affected by globalisation and, accordingly, react to it in a different way. Also, different themes in higher education policies and institutional strategies are affected by globalisation in different ways. All these observations only add to the complexity of the relation between higher education and globalisation. An important point in the use of the term globalisation is that we need to know the answer to the following question: The globalisation of what? The what in this question can take a wide variety of social arrangements ranging from the very abstract to the very concrete. For higher education research, the main distinction is between the globalisation of higher education or the globalisation of other social arrangements. The globalisation of the economy, for instance, is important to higher education, but we are talking about something different than when we are discussing the globalisation of higher education. Furthermore, we need to indicate which part, group, or meaning of the university is globalising or is affected by globalisation. A final point is that we need to make a distinction between globalisation and the effects of globalisation. Globalisation sometimes is treated as an equivalent to managerialism, marketisation, decline of the welfare state, the collapse of democracy, commodification, or to a set of business practices. Using such definitions is mistaking globalisation with (potential) effects of globalisation. The process and its effects thus need to be unravelled, not equated. In equating the process of globalisation with its effects, ideological and normative views are frequently propagated. Quoting Toulmin (1999, p. 906), one might say that "globalisation is both a historical fact and a political football." Although taking a critical stance is one of the functions of academe, facts and prophecies should be presented as such and should not be entangled.

\section{REFERENCES}

Angell, N. (1911). The great illusion. New York: G. P. Putnam.

Appadurai, A. (1990). Disjuncture and difference in the global cultural economy. Public Culture, 2(2), 1-24. 
Appadurai, A. (1996). Modernity at large: Cultural dimensions of globalization. Minneapolis: University of Minnesota Press.

Barber, B. (1996). Jihad vs McWorld. New York: Ballantine.

Bauman, Z. (1998). Globalization: The human consequences. Cambridge, MA: Polity.

Beck, U. (2000a). What is globalization? Cambridge, MA: Polity.

Beck, U. (2000b). The cosmopolitan perspective: Sociology of the second age of modernity. British Journal of Sociology, 51(1), 79-105.

Beerkens, E. (2002). International inter-organisational arrangements in higher education: Towards a typology. Tertiary Education and Management, 8(4), 297-314.

Castells, M. (1996, 1997, 1998). The information age (Vols. I, II, III). Oxford, UK: Blackwell.

Castells, M. (2000). Materials for an exploratory theory of the network society. British Journal of Sociology, 51(1), 5-24.

Cerny, P. G. (1997). Paradoxes of the competition state: The dynamics of political globalisation. Government and Opposition, 32(2), 251-274.

Cerny, P. G. (1999). Globalisation and the erosion of democracy. European Journal of Political Research, 36(1), 1-26.

Currie, J. (1998). Introduction. In J. Currie \& J. Newson (Eds.), Universities and globalisation: Critical perspectives. London: Sage.

Enders, J., \& Fulton, O. (2002). Blurring boundaries and blistering institutions: An introduction. In J. Enders \& O. Fulton (Eds.), Higher education in a globalising world: International trends and mutual observations. Dordrecht, the Netherlands: Kluwer.

Friedman, T. L. (1999). The lexus and the olive tree; Understanding globalization. New York: Farrar, Straus and Giroux.

Habermas, J. (1996). The European nation-state: Its achievements and its limits. On the past and future of sovereignty and citizenship. In G. Balakrishnan (Ed.), Mapping the nation. London: Verso.

Hirst, P., \& Thompson, G. (1996). Globalization in question. Cambridge, MA: Polity.

Hoogvelt, A. (1998). Globalisation and the post-colonial world: The new political economy of development. London: Macmillan.

Huntington, S. (1996). The clash of civilizations and the remaking of world order. New York: Simon \& Schuster.

Kälvermark, T., \& van der Wende, M. C. (Eds.). (1997). National policies for internationalisation of higher education in Europe. Stockholm: National Agency for Higher Education.

Lash, S., \& Urry, J. (1994). Globalization and localization. In S. Lash \& J. Urry (Eds.), Economies of signs and space. London: Sage. 
MacKinder, H. J. (1904). The geographical pivot of history. Geographical Journal, 23(1), 421-442.

Ohmae, K. (1992). The borderless world: Power and strategy in the global marketplace. London: Harper Collins.

Ohmae, K. (1995). The end of the nation state: The rise of regional economies. New York: Free Press.

Robertson, R. (1992). Globalization: Social theory and global culture. London: Sage.

Sassen, S. (1991). The global city: New York, London, Tokyo. Princeton, NY: Princeton University Press.

Sassen, S. (2000). Territory and territoriality in the global economy. International Sociology, 15(2), 372-393.

Scholte, J. A. (1997). Global capitalism and the state. International Affairs, 73(3), 427-452.

Scott, P. (1998). Massification, internationalization and globalization. In P. Scott (Ed.), The globalization of higher education. Buckingham, UK: Open University Press.

Smith, A. D. (1990). Towards a global culture. In M. Featherstone (Ed.), Global culture: Nationalism, globalisation and modernity. London: Sage.

Toulmin, S. (1999). The ambiguities of globalization. Futures, 31(9/10), 905912.

van der Wende, M. C. (2001). Internationalisation policies: About new trends and contrasting paradigms. Higher Education Policy, 14(3), 249-260.

Wade, R. (1996). Globalization and its limits. In S. Berger \& R. P. Dore (Eds.), National diversity and global capitalism. Ithaca, NY: Cornell University Press.

\section{ABOUT THE AUTHOR}

Eric Beerkens graduated in spatial and environmental planning at the University of Groningen in the Netherlands. He started working at the Center for Higher Education Policy Studies at the University of Twente in 1998 and has mainly been involved in questions relating to internationalisation and globalisation of higher education. Since 2000, he has been working on a dissertation on the effectiveness of international interuniversity networks in higher education in Europe and Southeast Asia. This study will be finalised in early 2004. 